\title{
The value of a community of practice in the subject design process when embedding interactive oral assessments
}

\author{
Deborah Scheele, Amita Krautloher, Saeed Shaeri, Marie-Louise Craig, Ruth \\ Crawford \\ Charles Sturt University Charles Sturt University Charles Sturt University
}

\begin{abstract}
This paper shares insights gained from members of a Community of Practice (CoP) who jointly designed and developed Interactive Oral Assessments (IOAs) for their online subjects in the first half of 2021 as part of a broader institutional project to improve online assessment practice across a multi-campus regional NSW university. Meetings of the CoP were conducted virtually to allow geographically dispersed staff to participate in and benefit from the sessions. The main aim of the $\mathrm{CoP}$ was to design online assessments that promote academic integrity and reflect authentic graduates' practice. The CoP members implemented new assessment regimes, tasks and rubrics for their respective subjects involved in the initiative and developed a suite of resources for future staff interested in trialling this approach. The outcomes highlight the value of a dedicated $\mathrm{CoP}$ in supporting academics to successfully embed a new assessment approach, and for encouraging uptake across the university courses.
\end{abstract}

Keywords: Community of Practice, Interactive Oral Assessments, Subject design, Backward design

\section{Introduction}

As Australian higher education providers continue to transition their programs and subjects to online delivery, assessment initiatives that encourage and support valid online assessment are increasingly trialed by subject design teams who develop the necessary pedagogical and technical skills and confidence to implement such initiatives within their institutions. This paper shares the assessment design experiences of members of a Community of Practice (CoP) formed to explore an alternative assessment method aimed at improving their assessment design and practices, promoting academic integrity, and developing assessments that reflect authentic graduates' practice.

The assessment method investigated by the COP was an online Interactive Oral Assessment (IOA) with members working together to design, develop and trial assessments in the first half of 2021 as part of a broader institutional project to improve online assessment practice across Charles Sturt University as a multi-campus regional NSW university. The CoP comprised four academics and one educational designer (ED), each from a different school across the university. An external mentor (Danielle Logan from Griffith University) provided expert input and ongoing guidance as members moved from novices to informed participants within the CoP.

\section{Foundational Concepts}

Contemporary academic development initiatives often include $\mathrm{CoP}$ models and initiatives aimed at fostering a collegial environment (Lave \& Wenger, 1991; Mercieca, 2017; Pyrko et al., 2017). These CoPs can be formal or informal and involve "mutually engaged social learning processes" (Pyrko et al. 2017 p. 406). After decades of research CoPs have come to be characterised by the following three structural elements; (i) shared repertoire, (ii) mutual engagement and (iii) joint enterprise (Lave \& Wenger, 1991; Wenger, 1988).

Assessment is a core element of the student learning experience (Boud, 2010) because it offers students the opportunity to demonstrate their learning, while teachers can observe how learners have understood and applied the content and skills of the learning experience. Assessment at Charles Sturt University is criterion-referenced, and standards based, and students' work is assessed against stated criteria and standards that align with the expected subject and course learning outcomes. Course standards require assessment tasks in each subject to 
form a cohesive assessment regime that sequences assessment as students develop knowledge and skills progressively across subjects. A range of assessment methods are used to ensure individual assessments provide opportunities for authentic learning situated in a real-life context that simulates the graduates' discipline area.

\section{Interactive Oral Assessment}

Interactive Oral Assessment (IOA) (Sotiriadou et al., 2019) is a method of assessment which requires the assessor and student(s) to adopt different roles within a given scenario-based conversation and interact with each other to deal with issues that develop during the conversation. This type of interaction is a form of experiential learning (Russell \& Shepherd, 2010) and as each student engages with the scenario, a unique interactive assessment emerges as the conversation evolves. The scenario-based conversation allows for concepts and ideas that may not be evidenced in formal examinations, multiple-choice tasks, or responsive written tasks.

\section{Structure}

This paper is structured to allow for polyvocal reflective narratives (Pithouse-Morgan \& Samaras, 2015, as cited in Diko \& Wessels, 2016) where CoP members' reflections (i.e., the 'findings') are presented to illustrate their experience of designing IOAs as part of the CoP. The written reflections begin by drawing on the voices of the members of the CoP to provide a "rich, ethnographic description" of the CoP being explored in this paper (Tummons, 2014, p.128). The voices are then overlaid onto the three structural elements of the Lave \& Wegner (1998) CoP framework to highlight how individual members experienced working within the CoP to design and implement a new assessment approach in their subjects.

When focusing on jointly refining the assessment design of subjects, CoP members were insider, close-up participants (Trowler, 2012) enacting a social constructivist approach toward thinking and reflecting on new information. This happened through discussion and social interaction, allowing for mutually agreed testing, and challenging ideas within a supportive group.

The methodology is suited for reporting on a $\mathrm{CoP}$ in a higher education context because it focuses on interpreting meaning and "seeing through others" eyes" (Bryman, 2016, p. 393) as well as exploring the "meaning that participants hold about the problem or issue" (Creswell \& Creswell, 2018, p. 182) thus allowing members to share their subjective experience, rather than objective observation. This supports an emergent design approach (Creswell \& Cresswell, 2014, p. 186) as it recognises the importance of capturing the richness of the experiences of the $\mathrm{CoP}$ members by inviting their individual reflective engagement on their experiences, rather than seeking a universal experience.

\section{Reflections}

Amita

I initiated the idea of introducing IOAs at our university to the Sub-Dean (Academic Development) in the Division of Learning and Teaching, and she nominated me to facilitate this CoP on IOAs. My interest in the IOA, as an educational designer and an ex-lecturer, stemmed from the constant challenge to look for assessments that enhance academic integrity (Bretag et al., 2019), help prepare students for their future workplaces, and support the development of students' lifelong learning skills to be successful as 21 st century graduates (OECD, 2018).

The goal for me was to facilitate the CoP through this pilot process, with the support of the external mentor, and develop my expertise in embedding IOAs in a variety of subjects along the way so that eventually we could be independent, and further promote the adoption of IOAs in a range of subjects across faculties.

The camaraderie has been so positive that academics are starting to question the worth of working on their subject design in isolation, or with just one ED. Similarly, working with the academics every step of the way, I realised that we could not have achieved this result without the CoP (Mercieca, 2017), a professional development session alone would not have been sufficient. I feel that we could either recommend the setting up of a $\mathrm{CoP}$ on various assessment approaches or expand the current $\mathrm{CoP}$ to be dedicated to the design of assessments. It would improve the efficiency of subject designs, as well as allow a small team of educational designers to manage a large pool of academics by leveraging the synergies (Mercieca, 2017) of the CoP. 


\begin{abstract}
Marie-Louise
I teach classical/biblical Hebrew so that students can learn to read the canonical corpus of writings that make up the Hebrew Bible in its original language. The original assessments were exams and translation assignments. It was not content that either really showed me what the students knew, what skills they had, or what ways they could apply their knowledge and skills. In an exam, a student with a limited vocabulary is unable to show their knowledge and application of grammar, etc. In translation assignments, the use of published English translations and secondary sources only showed that the student could do the research, not that they understood Hebrew. In addition, exams were difficult to administer with distance and online students. Finding a way to assess what students really could do with the language, motivated me to explore using an IOA as a capstone assessment in the final semester of Hebrew.
\end{abstract}

I loved being in the group. Although my colleagues did not understand the details of my subject, nor I theirs, it was empowering to discuss problems together, to find solutions together, and to practise skills on each other. I always left the sessions thinking: "I am not alone!" and "I can do this!"

\title{
Saeed
}

The engineering curriculum at our university, requires students to complete four one-year paid work placements after finishing three semesters of face-to-face, on-campus studies (Lindsay and Morgan, 2021). Alongside those periods of full-time employment, students must also complete a number of subjects, a group of which is a series of five subjects generally titled Engineering Portfolio (EP), and they are EP-Introductory, EP-Developing, EPConsolidating, EP-Advance, EP-Professional Engineer, each of which is run over one semester. The overall aim of those subjects is to guide students on how to collect evidence of their professional skill development at their workplace, and write claims of competency against certain elements/indicators of attainment, ideated from the Engineers Australia Competency Standards (link). While doing so, one of the categories of assessment items in the EP series is about self-evaluation and reflection on the competence development, for which an IOA has been adopted for the fourth subject in the series, and during its second iteration between March and July 2021.

I have benefitted a lot from being a part of the IOA CoP. I now have a better idea of how effective and beneficial a $\mathrm{CoP}$ can be, and it all goes to good mentoring and coordination, as well the willingness of the participants to immerse themselves in the process.

Ruth

The students I was keen to improve my assessment methods with were those studying nutrition in the exercise science degree. I heard about IOA at the 2020 education symposium at our university and it sounded like a great solution to some assessment challenges I faced. When teaching nutrition students, I often found myself marking written assessments and exams wishing I had the students sitting next to me so I could talk to them to find out if they really understood some content of our course. Concepts such as nutrition scope of practice and translation of nutrition knowledge into practice were often poorly expressed and left me with some doubt about a student's level of understanding. Written responses may have been 'technically correct' but with a sense of rote learning. Conversely, a response which includes some content written in their own words with some good examples, but poorly expressed also left me with some doubts about their level of understanding.

I implemented the IOA into my nutrition subject with little adjustment to the subject as it complemented well the existing written case study tasks. I provided support material and information for the students including the exemplar which we watched in a tutorial and marked using the rubric. To continue with this assessment, I need to refine the rubric and am looking forward to doing it again next year.

\section{Deborah}

The cohort in my subject are academics who have teaching roles within the university and are undertaking the subject as part of their professional development to strengthen their higher education learning and teaching practice and knowledge. As part of this subject, learners are required to explore disciplinary and online pedagogies that enhance the quality of their teaching and student learning, and they can choose modules that reflect their interest and discipline. Therefore, I considered that being involved in an initiative that exposed them to new ways of conducting and considering assessments was a great opportunity for them to build their academic and scholarly practice by observing and participating in an innovative and reflective assessment practice in a safe learning environment. The response from participants was overwhelmingly positive with all indicating they would use this practice in some form. 
The above reflections describe the fundamental characterises of the $\mathrm{CoP}$ and provide context for how this community of practice may be understood (Tummons, 2014). Thematic analysis of further reflections identified three overarching themes being; i) $\mathrm{CoP}$ activity- what happened when the CoP met, ii) benefits and opportunities for individuals and, iii) roles played by members. These themes closely align to the structural elements of the Lave \& Wenger (1991:1988) CoP framework as shown in Table 1.

Table 1. Thematic analysis and CoP framework

\begin{tabular}{llll}
\hline CoP framework & $\begin{array}{l}\text { Shared domain of } \\
\text { interest (joint } \\
\text { enterprise) }\end{array}$ & $\begin{array}{l}\text { Members engage in joint } \\
\text { activities and help each other } \\
\text { (mutual engagement) }\end{array}$ & $\begin{array}{l}\text { Members as practitioners who } \\
\text { develop shared resources } \\
\text { (shared repertoire) }\end{array}$ \\
\hline $\begin{array}{l}\text { Themes identified } \\
\text { from reflections }\end{array}$ & CoP activity & $\begin{array}{l}\text { Benefits and opportunities for } \\
\text { individuals }\end{array}$ & Roles played by members \\
\hline
\end{tabular}

Therefore, the CoP framework will be used to describe the joint enterprise, unpack the shared repertoire, and highlight the mutual engagement of the CoP (Tummons, 2014).

\section{Shared Domain of Interest (Joint Enterprise)}

In the COP the shared domain of interest (where the activity of the CoP was focused) was the re-design of online subject assessment. There were a range of dimensions of online assessment that $\mathrm{CoP}$ members were interested in exploring, including investigating methods of assessment that promote academic integrity, providing opportunities for students to engage in authentic contexts and allowing students to apply knowledge rather than simply respond in ways that demonstrate 'recall'. Further, members wanted to explore an alternative online assessment regime that could reduce the pressure generated by limitations on the time available for marking assessment tasks.

This joint enterprise involved members sharing the learning outcomes for their subject and working collaboratively to review the requirements and identify a realistic and authentic scenario. The scenario drew together key subject learning outcomes and acted as a vehicle (Mouraz et al., 2013) to allow participants to display their knowledge and understanding of the content and enable the assessor to gather assessment evidence.

\section{Marie-Louise}

I began with the goal of changing one assessment and ended up rethinking every assessment and how I taught the subject. Using the IOA as the capstone assessment made me consider what a Hebrew scholar looked like (the subject outcomes) and how I could prepare students to be well-rounded readers of Hebrew literature, who could discuss, apply, and adapt linguistic and literary information in a real-life situation. I changed the earlier assessments to provide the necessary steps for gaining these skills. Then I adjusted how the subject was taught, not just the order of the content, but the content itself and how I taught it.

The rubric was the second task we undertook, the first being the scenario of the IOA. For me, the rubric was developed in a cycle: a first draft, editing it with the ED, sharing with the CoP, seeing other rubrics in the CoP, a second draft, more editing with the ED, etc. This was an essential process and the difference between the first and second drafts, and the one used in the IO was dramatic.

\section{Saeed}

Initially, the reflection assessment was in a written form in the EP-Consolidating subject, with limitations on the number of competency elements, the number of pages/words, and the use of non-textual components (e.g., evidence of claims). However, after the first offering, it was made clear that the written reflection limits students in terms of discussing all aspects of their competence development reflection, as there was no space for creativity. Even a change to a video recording method in the first offering of the EP-Advanced subject did not solve the issues and improved the outcomes, as many of the students recorded a very basic video, with themselves reading directly from a prepared script, while there was no indication of spontaneous, deep, critical discussion of the chosen competence element. Equally important, the effectiveness of the exchange of feedback between the marker/assessor and the students in the usual written form of the feedback was not measurable in either of the iterations. 
Given the above, in the 2021 offering of the EP-Advanced subject, the idea of an IOA guided the re-design for the reflection assessment item, as well as modification of other assessment items in the subject to ensure IOA was properly scaffolded.

Ruth

I found the CoP that supported the pilot use of IOAs the key to my success in implementing this change. The process of working together on our scenarios, rubrics and exemplars was vital to my ability to bring in such a significant change to the assessment of my nutrition subject. Another key to this success was having the support of an educational designer who developed and shared resources and 'how to' guides for all aspects of an IOA.

\section{Deborah}

Working collaboratively with colleagues to review, develop and refine the assessment scenarios and rubrics was enjoyable, rewarding, and surprisingly efficient. When we each brought our learning outcomes and assessments to the CoP gatherings, the input was varied yet coherent and easy to implement. Working with colleagues in the CoP prompted me to develop an assessment regime for this subject to give students the opportunity to demonstrate how much they know as opposed to me testing what they may have missed. With the input of the $\mathrm{CoP}$, my redeveloped assessment scenario reflected the professional context of my cohort, thus ensuring authentic assessment.

Although members joined the $\mathrm{CoP}$ to meet subject assessment design goals, it is clear from the above reflections that this experience has given each participant so much more than they expected in terms of how they use design strategies that support authentic, student focused learning and assessment. One of the successful outcomes of this $\mathrm{CoP}$ is that subject assessment regimes were investigated jointly and collegially and resulted in new assessment regimes, tasks, and rubrics for all subjects.

\section{Members Engage in Joint Activities and Help Each Other (Mutual Engagement)}

In this COP members regularly engaged in joint activities and worked together to help each other develop the necessary pedagogical and technical skills and confidence to implement IOA within their subjects. The mutual engagement resulted in a range of benefits and opportunities for the $\mathrm{CoP}$ members as expressed in the following reflections.

\section{Marie-Louise}

This CoP worked because of the diverse people in the community: the subject designer whose dream it was in the first place and who understood systems; the external mentor with all her experience, research and examples; the Sub-Dean Academic Development who brought to the group expertise in assessment and backward design; the lecturers themselves who all came from different faculties.

I found the CoP essential to the whole process. Without the community, I would have missed very important planning and practising elements. The fact that the external mentor and the ED were there to set up a path for us to follow made the difference between success and failure. They guided us through several steps, the importance of which I did not recognise at first, but later realised made the difference between success and failure.

\section{Saeed}

Initially, I was not aware of any approach similar to an IOA in terms of effectiveness and broader benefits beyond the scope of my subject. However, as a missing piece, upon being introduced by the ED to the IOA concept, and also pursuing some samples in action, the decision was easy to implement this approach for my subject. Likewise, I have never been a part of a $\mathrm{CoP}$ through which a much better outcome could be achieved collegially than in solo. The way that our IOA CoP worked has been completely different to the type of collaboration and co-creation of information that is common in my engineering practice and discipline-based research, and that has been the most important aspect in my expertise development and the sense of being supported by peers with almost the same level of expertise.

The appointed ED was influential in several aspects. For instance, some of the advice/suggestions from the external mentor were not easily transferable to a different institution's technological infrastructure. Accordingly, the ED was effective in finding alternative options for implementation. Furthermore, the ED assisted in ensuring the investment of time by the participants would make a strongly positive return, not only for the initial group of participants, but also for the next phase of the IOA implementation. For example, the ED collated the ideas for 
items of a marking rubric or establishment of a practical booking system. In the process, the external mentor was also instrumental in expanding on the details of the approach and providing continuous feedback to the participants for every stage of their development. Simply, attending the weekly meeting and listening to her comments about other works, was invaluable to provide me with more options and questions that I initially had by myself.

Ruth

The idea of being able to have an authentic scenario-based verbal interaction with the students sounded like a great solution to enable students to truly demonstrate their level of knowledge and understanding. In addition to this authenticity, the efficiency of this assessment method appealed to me. The symposium presentation included the 'selling point' that a well-constructed 10-minute IOA would take 5 minutes to mark and was equivalent to a few thousand word written assessment. This sounded too good to be true! Marking written assessments takes me two to three times longer than I'm allocated in my workload and becomes such a chore with many late nights of work to complete them. The idea that this task may only take 5 minutes to mark made me want to get involved.

I was delighted to find that it was true - IOAs are quick to mark. Whilst I took longer than the 'advertised' 5 minutes to mark them, it was significantly quicker than my marking of written tasks. I found it took 10-15 minutes to mark each IOA, and a real bonus was all these were done during usual work hours. Improving the criteria in my rubric will make this more efficient next time. Whilst more time was spent preparing for these assessments than for a written assessment task, there was an overall time efficiency of this method - another important reason I will keep using them. The authentic conversation also delivered on providing clear evidence about the student's level of understanding.

\section{Deborah}

Participating in the CoP has been rewarding and energising for me and I especially enjoyed being part of a cross-disciplinary community and having the opportunity to see different assessment methods and approaches being implemented. Although unfamiliar with the nuances of the subject matter I found working with the learning outcomes prompted me to consider what I could do differently in my subject.

\section{Amita}

The members have developed skills and confidence in implementing IOAs. These early adopters have now become champions of this assessment approach within their School and Faculty. It has encouraged members to step outside the box of traditional assessment approaches and take a fresh look at how best to assess student learning. They are now being sounding boards for their colleagues by sharing their knowledge. As a result, it has created a ripple effect, where other academics are starting to join the CoP through the influence of the academics in the first pilot. The CoP has also rejuvenated interest in scholarly activities, especially collaborative publications, and conference presentations. It has broken down the barriers created by silos that form around faculties, schools, and disciplines.

The independent voices represented in these reflections come together to say 'we could not have done it without the CoP'. These voices correspond with Mercieca's (2017, p. 59) findings that a CoP offers a "practical way of developing a scholarship of teaching and learning at a grassroots level" and illustrate the benefits and opportunities CoPs can foster by building multidisciplinary ways of knowing and expertise across a range of disciplines and faculties.

\section{Members As Practitioners Who Develop Shared Resources (Shared Repertoire)}

Participating in the CoP allowed members to take on various roles and build their skills, confidence and expertise in teaching and learning practices. Although all members of the CoP contributed to developing a shared repertoire of resources, experiences, tools, and information to support the re-design of their subject assessment regimes the process of continually evolving and improving the emerging IOAs was led by the ED who consistently focused on the assessment design and provided guidance and support to members. Suggestions were offered and considered within the CoP meetings and individual academics worked offline with the ED to refine their scenario and present it to the $\mathrm{CoP}$ for further comments/input.

Once a scenario that represented authentic practice in the discipline was developed, the CoP members supported each academic to prepare an exemplar IOA recording to be used as a resource to support the assessment process. The CoP members then collaborated on developing the assessment task, supporting criteria, and performance 
standards (taking the form of a rubric), to ensure students' marks reflect their ability to meet the required standard.

\section{Marie-Louise}

We practised preparing an exemplar on each other and in front of each other and discussed how we went. For my exemplar, at first the other members of the CoP tried being my examiners. This did not work because they are not Hebrew scholars, but we learned more about the difference between an IOA and a presented paper. The best learning for me, however, was when $\mathrm{RC}$ and her colleague did a recording of their IOA in front of us and we discussed it. As a result of this discussion, $\mathrm{RC}$ changed her scenario and the role she would play in it and recorded the new scenario. We learned then that an IOA is not a viva voce, and that a well-thought-through scenario can make all the difference. I also learned that a $\mathrm{CoP}$ is a fantastic place to do this kind of experimenting.

\section{Saeed}

Specifically, preparing an exemplar for an IOA to be shared with students was the most informative part of our $\mathrm{CoP}$. Hearing the feedback not only from the external advisor, but also from other members of our CoP, as well as the way each of the exemplar recordings was done, assisted me significantly, to prepare my exemplars (for which my students expressed an overwhelmingly high satisfaction).

The assessment scenario was designed as if each student would be a junior graduate engineer who would like to apply to Engineers Australia, to be recognised as a registered professional engineer. The title of the assessment was also chosen as 'a journey towards higher-level competencies'. In doing so and similar to the finding of Sotiriadou et al. (2019), not only did IOA involve an authentic conversation and a genuine discussion between students and assessors about a particular scenario, but it also proved to be a lot more effective both in terms of the assessor's success and effectiveness in the evaluation and marking, as well as the effective exchange of feedback (Shaeri et al., 2021). I also learned a lot from other participants, listening to their challenges, their adopted approaches, and how they re-designed their respective subjects.

\section{Ruth}

Preparing the scenario and recording the exemplar was key to my understanding of the IOA format. My initial approach was like an oral exam. With coaching from our external mentor, I adjusted my approach to be consistent with an IOA. The key was 'unscripting' the assessment and taking the leap of faith that an authentic conversation could cover the content required and it did! Such a powerful experience.

\section{Deborah}

This experience reminded me that high quality assessment design is the core feature of a learning and teaching process that fosters learning regardless of the subject content. Participating in the $\mathrm{CoP}$ showed me that although assessment happens in a variety of contexts and learning environments, the methods chosen has a significant influence on how students learn, what they achieve and their overall subject and course experience. My colleagues in the $\mathrm{CoP}$ inspired, helped, and guided me to create a better assessment - in my world that is a great outcome!

\section{Amita}

I took a structured approach in planning a few steps ahead, had resources or guidelines ready for embedding IOAs, and complied with our university's systems and software tools. It helped the academics to meet the subject delivery requirements as well as that of the IOA. At our university, this starts with the Subject Outline (SO) submission deadline, and hence it was our primary focus in the initial meetings.

As the members of this CoP were geographically dispersed, we met synchronously each week via Zoom and worked on various aspects of the subject design. This regular, technology-enabled synchronous contact was crucial as it fostered ongoing engagement and connections and supported continual progress as the assessment design evolved through participation in the CoP. Simultaneously, I set up an interface in the LMS to allow asynchronous engagement and this platform became the reservoir for all resources and was available to anyone interested in looking, without having to join the $\mathrm{CoP}$. The $\mathrm{CoP}$ developed a range of resources that will serve as an exemplar or resources to others, including a range of subject designs, task descriptions, rubrics, simulations, and instructions for academics to use various software tools to facilitate the implementation of IOAs. 
It is clear from the above reflections that the opportunity to participate in a supportive community that shared knowledge, gave and received critical, collegial feedback and acted as sounding board for their colleagues developed members' pedagogical understanding and provided a safe space to make mistakes.

\section{Discussion}

The CoP structural elements identified by Lave \& Wenger (1991) were evident in the activity of the CoP as members regularly engaged in joint activities and worked together to discuss and develop a shared repertoire of resources, experiences, tools, and information that supported the re-design of their subject assessment regimes. Further, consistent with contemporary studies of CoP in higher education contexts, the CoP presented in this paper provided a collaborative structure for exploring and experimenting by supporting and encouraging member behaviours that allowed for the sharing and transfer of factual, conceptual, theoretical, and metacognitive knowledge (Smith et al., 2017; Sheryl et al., 2014). This transfer deepened the knowledge of all members and occurred as members critically reviewed information and asked each other questions (Aljuwaiber, 2016; Lave \& Wenger, 1991; Reaburn \& McDonald, 2016; Wenger-Trayner \& Wenger-Trayner, 2015).

The connection, conversation, and collegial sharing of practice that happened during this CoP gave members a sense of confidence and positively impacted on the quality of their practice which corresponds with the CoP literature that observes that 'a person's professional identity is boosted through experiencing success in their own teaching and learning context as a result of their involvement in a CoP' (Mercieca, 2017, p. 13) and that CoPs are "characterized by sustained thinking together that is enriched by less intensive forms of participation" (Pyrko et al., p. 404). The reflections independently and unanimously endorse the value of the ED and other expert guidance to the CoP, as well as individual members.

As articulated in the backwards design approach (Wiggins \& McTighe, 2005) to course and subject design an important aspect of assessment design is defining clear criteria and developing differentiated performance standards. In line with this approach, the assessment evidence required by the learning outcomes is identified as the first goal of the assessment design process. For the CoP members, IOA was a new method of assessment to design, implement and mark yet each member found that helped them to better evaluate the depth of knowledge that students drew on when participating in the assessment conversation.

The online environment enabled the facilitation of the IOA via face-to-face, synchronous interaction between the assessor and the student without external distractions (Russell \& Shepherd, 2010). Further, the ED ensured academics could access an institutionally supported interface for setting up, running, and managing the IOA that complied with institutional process requirements, including moderation, privacy, and storage.

\section{Limitations}

As the contributors to the reflections presented are all from a single higher education institution, they tend to share mutually agreed conventions. While this supports a constructivist approach which holds that knowledge is essentially subjective and constructed from perception and mutually agreed conventions, it has the possible disadvantage of leading to a homogenous response.

We also acknowledge the limited number of participants in the first trial of the IOAs, and ponder on the different outcomes that may have resulted from a larger pool of participants. Further investigation is required to assess the ability of one ED and an external mentor to support a larger pool of academics keeping in mind the 'emergent an improvised' learning that happens within a communities of practice framework and "Lave and Wenger's rejection of a language of formal instruction” (Tummons, 2014 p. 129).

When compiling this paper, we strived to achieve a variety of voices and experiences by weaving the voices from the reflections through the discussions and while the self-reflective narrative is appropriate for this paper, the authors acknowledge that it can disrupt the flow of the text.

\section{Conclusion}

The reflections demonstrate how CoP members drew on their colleagues' insights and experiences to jointly improve their learning and teaching practices (in this case, the assessment design) and learn from each other. 
Further, they show that diverse roles within the CoP add value - the external mentor provided an expert view, the ED guided the design and harnessed technology to provide support, the leadership from the Sub-Dean (Academic Development) affirmed the CoP and validated pathway, and the academics engaged with cross disciplinary professional learning.

It is also clear that the initiative described in this paper contributed to improved assessment practice at the university as the CoP developed the skills to implement IOAs in the nominated subjects. The resources developed and insights gained will foster and support better approaches to assessment and address the concomitant need to assess students in ways that test their skills and knowledge in tasks that resemble the contexts they will be working in on graduation.

Together, we hope this paper on the experience of designing and developing IOAs as part of a CoP helps future structured research focusing on a comprehensive and holistic exploration of participants' experiences, and students' impacts. This paper is a prospective project indicative of our expected future work and it is expected that the future research results will provide rich, deep, and perhaps startling insights into academics' inclination, confidence and interest in engaging in CoPs as a model for learning design and professional development. Subsequently, the insights gained could inform further studies in similar organisations with a larger number of participants.

With the growth of online environments and tools that support scenario-based learning and assessment (including web-based role play, simulated environments and immersion applications) that allow for sophisticated and complex online interactions, the distinction between customised online role-play environments and standard learning management system (LMS) environments could become irrelevant (Russell \& Shepherd, 2010, p. 1000) and if we "aren't ready for that yet, our kids are gonna love it" (Zemeckis, 1985).

\section{References}

Aljuwaiber, A. (2016). Communities of practice as an initiative for knowledge sharing in business organisations: a literature review. Journal of Knowledge Management, 20, 731-748 https://doi.org/10.1108/JKM-12-20150494

Boud, D. and Associates. (2010). Assessment 2020: Seven propositions for assessment reform in higher education. Sydney: Australian Learning and Teaching Council. http://www.assessmentfutures.com/

Bretag, T., Harper, R., Burton, M., Ellis, C., Newton, P., Rozenberg, P., Saddiqui, S., \& Van Haeringen, K. (2019). Contract cheating: a survey of Australian university students. Studies in Higher Education, 44(11), 1837-1856. https://doi.org/10.1080/03075079.2018.1462788

Bryman, A. (2016). Social research methods (5th ed.). Oxford University Press.

Creswell, J. W., \& Creswell, J. D. (2018). Research design: Qualitative, Quantitative, and Mixed methods approaches (5th ed.). SAGE Publications, Inc.

Diko, N., \& Wessels, E. (2016). Polyvocal professional learning through self-study research by Kathleen Pithouse-Morgan and Anastasia Samaras. Educational Research for Social Change, 5(2), 165-168.

Lave, J., \& Wenger, E. (1991). Situated learning: Legitimate peripheral participation. Cambridge University Press. https://doi.org/10.1017/CBO9780511815355

Lindsay, E. D., \& Morgan, J. R. (2021). The CSU engineering model: educating student engineers through PBL, WPL and an online, on demand curriculum. European Journal of Engineering Education, 1-25. https://doi.org/10.1080/03043797.2021.1922360

McMillan, J. H., \& Wergin, J. F. (2010). Understanding and evaluating educational research (4th ed.). Pearson/Merrill.

Mercieca, B. (2017). What is a Community of Practice? In: J. McDonald, \& A. Cater-Steel (Eds.), Communities of Practice. Springer, Singapore. https://doi.org/10.1007/978-981-10-2879-3 1

Mouraz, A., Pereira, A., \& Monteiro, R. (2013). The Use of Metaphors in the Processes of Teaching and Learning in Higher Education.

OECD. (2018). The future of education and skills: Education 2030. https://www.oecd.org/education/2030/E2030\%20Position\%20Paper\%20(05.04.2018).pdf

Pyrko, I., Dörfler, V., \& Eden, C. (2017). Thinking together: What makes Communities of Practice work? Human Relations, 70(4), 389-409. https://doi.org/10.1177/0018726716661040

Reaburn, P., \& McDonald, J. (2016). Creating and Facilitating Communities of Practice in Higher Education: Theory to Practice in a Regional Australian University. 121-150. https://doi.org/10.1007/978-981-10-2879$\underline{36}$ 
Russell, C., \& Shepherd, J. (2010). Online role-play environments for higher education. British Journal of Educational Technology, 41(6), 992-1002. https://doi.org/10.1111/j.1467-8535.2009.01048.x

Shaeri, S., Logan, D., \& Krautloher, A. (submitted) Evaluation of competency development using interactive oral assessment. Submitted as a full paper to be presented at the Australasian Association of Engineering Education (AAEE) Conference. 5-8 December 2021, Perth, Australia.

Sheryl, B., Maria, J., Melanie, B., \& Grzegorz, M. (2014). Forming communities of practice in higher education: a comparative analysis. International Journal of Multidisciplinarity in Business and Science, 2(2), 3.

Smith, S. U., Hayes, S., \& Shea, P. (2017). A critical review of the use of Wenger's Community of Practice (CoP) theoretical framework in online and blended learning research, 2000-2014, Online Learning 21(1), 209-237. https://doi.org/10.24059/olj.v21i1.963

Sotiriadou, P., Logan, D., Daly, A., \& Guest, R. (2019). The role of authentic assessment to preserve academic integrity and promote skill development and employability. Studies in Higher Education, 1-17 https://doi.org/10.1080/03075079.2019.1582015

Tummons, J. (2014). Learning Architectures and Communities of Practice in Higher Education. In Theory and Method in Higher Education Research II. Emerald Group Publishing Limited. https://doi.org/10.1108/S1479-3628(2014)0000010012

Trowler, P. (2012). Doing Insider Research in Universities: A short guide. http://www.amazon.co.uk/DoingInsider-Research-Universities-Education/dp/1500672726

Wenger-Trayner, E., \& Wenger-Trayner, B. (2015). Communities of practice: A brief introduction. https://wenger-trayner.com/resources/

Wiggins, G. P., \& McTighe, J. (2005). Understanding by design (Expanded 2nd ed.). Association for Supervision and Curriculum Development.

Zemeckis, R. (1985). Back to the Future. Universal Pictures.

Scheele, D., Krautloher, A., Shaeri, S., Craig, M-L., Crawford, R. (2021). The value of a community of practice in the subject design process when embedding interactive oral assessments. In Gregory, S., Warburton, S., \& Schier, M. (Eds.), Back to the Future - ASCILITE '21. Proceedings ASCILITE 2021 in Armidale (pp. 93-102). https://doi.org/10.14742/ascilite2021.0113

Note: All published papers are refereed, having undergone a double-blind peer-review process.

The author(s) assign a Creative Commons by attribution licence enabling others to distribute, remix, tweak, and build upon their work, even commercially, as long as credit is given to the author(s) for the original creation.

(C) Scheele, D., Krautloher, A., Shaeri, S., Craig, M-L., Crawford, R. 2021 